2017 April Issue - Editorial / Tatiana

\title{
Systems, organizations and students
}

The papers in the April issue can be divided in two groups according to their focus: those addressing the organizational and systemic dimensions in higher education (the entrepreneurial university and the public/private divide); and those focusing on contemporary students' issues such as fostering global competences, online learning, and happiness.

The first paper introduces the new section on Classics in Higher Education Studies. The Classics section is conceived of as a platform for reflecting on the evolution of the field by revisiting the foundational works of eminent scholars and highlighting their potential to guide future research. Gary Rhoades and Bjorn Stensaker discuss the concept of the entrepreneurial university by Burton Clark (1998). Both authors worked with Burton Clark and have been able to elaborate on the impact of his work for theory, policy and practice, on its influence in the North American and European contexts, and to highlight the enduring significance of his ideas for future research. Salient but under-investigated topics have been focused upon by Heather Lea Harvey, Sanjai Prahoo and Mohammad Santally, who started their research by problematizing gender differences in online learning among millennial students. Their analysis of 834 respondents with a mixed-method research design leads to counterintuitive findings. While gender plays no significant role among technology-knowledgeable millennials, the latter appear to give more importance to the reputation and infrastructure of their university, as well as to the empathy of their instructors. Qjan Meng, Chang Zhu and Chun Cao have addressed the propensity for global competence of Chinese students in public research intensive ("985 project universities") and regional universities ("211 project universities") in China. Analysing more than 2600 respondents in a survey, they found that higher education institution type, gender, geographical location, and disciplinary fields are related to students' inclination to global competence. These findings build on previous research published in HEQ by the authors (Cao, Zhu and Meng 2016). By using the theory of organizational publicness Young-Joo Lee explores one of the tensions of the contemporary university, required to become increasingly relevant to society, while at the same time differentiating its funding sources due to stagnating or shrinking public funding. The author argues that the more universities depend upon private funding - such as student fees - the less they are willing or able to allocate resources to their services function, in particular to community engagement. Alex Elwick and Sara Cannizzaro provide a critical discussion around the concept of happiness in higher education and on how this has been colonized by an increasingly consumerist ideology, where universities tend to conflate students' happiness and satisfaction. This conceptual paper builds on the literature on happiness in education as well as on critical studies of education.

\section{References}

Cao, C., Zhu, C. and Meng, Q. (2016) A Survey of the Influencing Factors for International Academic Mobility of Chinese University Students, Higher Education Quarterly, 70(2), 200-220.

Clark, Burton C. (1998) Creating entrepreneurial universities. Organizational pathways to transformation, Bingley (UK): Emerald. 